\title{
BMJ Open Caesarean sections and health financing: a global analysis
}

\author{
Ilir Hoxha (D) ,,2 Günther Fink ${ }^{3,4}$
}

To cite: Hoxha I, Fink G. Caesarean sections and health financing: a global analysis. BMJ Open 2021;11:e044383. doi:10.1136/ bmjopen-2020-044383

- Prepublication history and additional supplemental material for this paper are available online. To view these files, please visit the journal online (http://dx.doi.org/10.1136/ bmjopen-2020-044383).

Received 01 September 2020 Accepted 23 April 2021

\section{Check for updates}

(c) Author(s) (or their employer(s)) 2021. Re-use permitted under CC BY-NC. No commercial re-use. See rights and permissions. Published by BMJ.

${ }^{1}$ Kolegji Heimerer, Pristina, Kosovo

${ }^{2}$ The Dartmouth Institute for Health Policy and Clinical Practice, Lebanon, New Hampshire, USA

${ }^{3}$ Swiss Tropical and Public Health Institute, Basel,

Switzerland

${ }^{4}$ University of Basel, Basel, Switzlerland

Correspondence to

Dr llir Hoxha;

ilir.s.hoxha@gmail.com

\begin{abstract}
Objectives The objective of this study is to explore the association of health financing indicators with the proportion of births by caesarean section (CS) across countries.
\end{abstract}

Design Ecological cross-country study.

Setting This study examines CS proportions across 172 countries.

Main outcome measures The primary outcome was the percentage excess of CS proportion, defined as CS proportions above the global target of $19 \%$. We also analysed continuous CS proportions, as well as excess proportion with a more restrictive $9 \%$ global target. Multivariable linear regressions were performed to test the association of health financing factors with the percentage excess proportions of CS. The health financing factors considered were total available health system resources (as percentage of gross domestic product), total contributions from private households (out-of-pocket, compulsory and voluntary health insurance contributions) and total national income.

Results We estimate that in 2018 there were a total of 8.8 million unnecessary CS globally, roughly two-thirds of which occurred in upper middle-income countries. Private health financing was positively associated with percentage excess CS proportion. In models adjusted for income and total health resources as well as human resources, each 10 per cent increase in out-of-pocket expenditure was associated with a 0.7 per cent increase in excess CS proportions. A 10 per cent increase in voluntary health insurance was associated with a 4 per cent increase in excess CS proportions.

Conclusions We have found that health system finance features are associated with CS use across countries. Further monitoring of these indicators, within countries and between countries will be needed to understand the effect of financial arrangements in the provision of CS.

\section{INTRODUCTION}

Caesarean section (CS) rates have been increasing rapidly over the past decades at the global scale, with remarkable variation both within and between countries. ${ }^{1-15}$ Such medical practice variation, in general, implies inefficient use of resources, that is, patients may not get what they need (underuse) or will get medically unnecessary care (overuse). ${ }^{1617}$ Empirically, CS rates between 9 to 19 per cent have been associated with improved health outcomes for mother and babies. ${ }^{5}$ 18-20 As
Strengths and limitations of this study

- Our study benefits from a large sample size, using information from 172 countries.

- The ecological nature of our study means that we cannot make definitive statements about causality in considering the relationship between the variables of interest.

- Although we used some of most reliable internationally available data sources, the quality of such data may not be entirely uniform across countries included in the analysis.

- We have been able to adjust only for some confounders in our statistical models. There are other macro level factors that do play a role that we could not account for in our analysis.

such, rates below 9 per cent are likely to represent underuse, while rates above 19 per cent likely represent overuse and may cause more harm than benefits to mothers and children, leaving aside the substantial additional cost and burden to the health system. ${ }^{1562122}$ Overuse of procedures like CS is likely to take away resources that could be used for other beneficial procedures and care.

As with all healthcare utilisation measures, overuse of delivery-related resources is a manifestation of the effect of a range of factors influencing health system performance, including health system structure and financing, medical practice patterns and patient preferences and behaviours. ${ }^{123}$ On the supply side, it can be a manifestation of availability of resources, that is, supply sensitive care, ${ }^{17}$ where more resources available mean more care provided, and/or provider behaviour, that is, supplier induced demand. ${ }^{24}$ Recent studies have highlighted the relevance of financing and incentives to the overuse of CS. ${ }^{25-27}$ In many settings, payment mechanisms or reimbursement systems provide a financial incentive for providers to deliver by CS rather than vaginally. ${ }^{25-27}$ For example, hospitals incentivise, via time-pressures ${ }^{28} 29$ or scheduling policies, ${ }^{30} 31$ insurers via payment models like fee for service ${ }^{32-34}$ or higher 
reimbursements rates for CS. ${ }^{35} 36$ In developing countries, this can also happen via informal rewards. ${ }^{37}$

Health sector financing approaches are complex and highly heterogeneous across countries, ranging from full government financing to mandatory insurance contribution and direct out-of-pocket payments. Modalities through which health sectors are financed affect how resources are spent, and how care is delivered. It is also likely that patients have more influence on provider behaviour in settings where the majority of healthcare costs are paid out-of-pocket than in settings where the entire health sector is centrally controlled and paid by government resources. In this paper, we explore the association of health financing indicators with caesarean proportions across countries using the most recent data on CS proportions and financial indicators. Our primary hypothesis was that reliance on private payment mechanisms would increase pressure on providers to use CS through one of two main mechanisms: first, by reducing governmental control over the services provided and second, by increasing entitlement and relative bargaining power of patients who may have personal preferences for CS.

\section{METHODS}

\section{Data}

We used data from several sources including Global Health Expenditure Database and Global Health Observatory $(\mathrm{GHO})$ data from the WHO as well as the World Bank Open Data. The Global Health Expenditure Database of the WHO provides data on health spending for close to 190 member countries from 2000 to 2018. This is an annually updated database where the WHO works collaboratively with member countries. The GHO is also a WHO gateway to health-related statistics for its 194 member countries. GHO country data includes all country statistics and health profiles that are available within the WHO. The World Bank's data catalogue provides access to over 3000 data sets and 14000 indicators and includes microdata, time series statistics and geospatial data. A list of all data sources is provided in the online supplemental appendix.

\section{Outcome variable}

The primary outcome variable was the percentage excess of C.S. Based on the most recent estimates, ${ }^{5}$ we used a CS proportion of 19 per cent as our reference, and considered all births delivered via CS above this level as excess. Specifically, we coded percentage excess CS (the proportion of deliveries in 2019 that exceeded $19 \% \mathrm{CS}$ ) as zero if a country has a proportion $\leq 19$ per cent, and as the actual proportion minus 19 per cent when the proportion exceeds this target. We also analysed percentage excess of CS using a 9 per cent benchmark ${ }^{20}$ and (continuous) CS proportions as secondary outcomes.

\section{Exposure variables}

Our primary exposure variables of interest are private contributions to health financing. Private contributions comprise three types of private health-related expenditures: (1) mandatory contributions to health insurance schemes; (2) voluntary contributions to (additional) insurance schemes and (3) out-of-pocket payments. We first considered a variable that combines all three variables, and thus measured total private contributions as percentage of total current health expenditure. In a second step, we analysed each of these three components separately, that is, included separate variables for mandatory contributions, voluntary contributions and out-of-pocket payments, all expressed as per cent of total current health expenditure. Mandatory contributions to health insurance are the primary source of health financing in insurance-based systems such as the ones in Germany, Switzerland or the USA, and most typically directly collected through employers in high-income settings. Voluntary insurance schemes are largely absent in countries such as Cuba, Jordan or Norway, but play a significant role in other settings. In many European countries such as Austria and Switzerland, voluntary insurance covers between 5 and 10 per cent of health expenditure-in Brazil, voluntary insurance contracts cover over one-third of total expenditure. Voluntary insurance generally covers premium services (such as fast access to doctors and private rooms) but in some cases can also reduce out-of-pocket co-payments. Out-of-pocket payments exist in all countries but range from less than 1 per cent in Kiribati and Nauru to close to 80 per cent in Armenia and Azerbaijan. The full data used in the analysis is provided in the online supplemental appendix.

\section{Statistical analysis}

We started by presenting the global distribution of CS proportions graphically. In a second step, we showed CS proportions as well as the estimated total CS percentage excess relative to the 19 and 9 per cent targets. Following the World Bank's country classification, we divided countries into high, upper middle, lower middle and low income countries and separately computed excess shares and number for each country-income group. In a third step, we examined the association of CS percentage excess with health financing mechanisms. We first estimated ordinary least squares regression models with percentage excess CS, using 19 and 9 per cent as benchmarks, as well the overall CS proportion as outcome and total private contributions as exposure variable. We then estimated a similar model where we included separate variables for compulsory, voluntary and outof-pocket payments. In both models, we controlled for income per capita and general size of the health sector to reduce potential confounding biases. To further address residual confounding concerns, we estimated two additional models that also controlled for the proportion of deliveries made by skilled birth attendants (model 3) as well as the health systems human resources (model 4). All confounding variables included have been shown to predict variation in medical practice,${ }^{17}$ such as variation in CS provision. ${ }^{1}$ To address missing data on some of the 


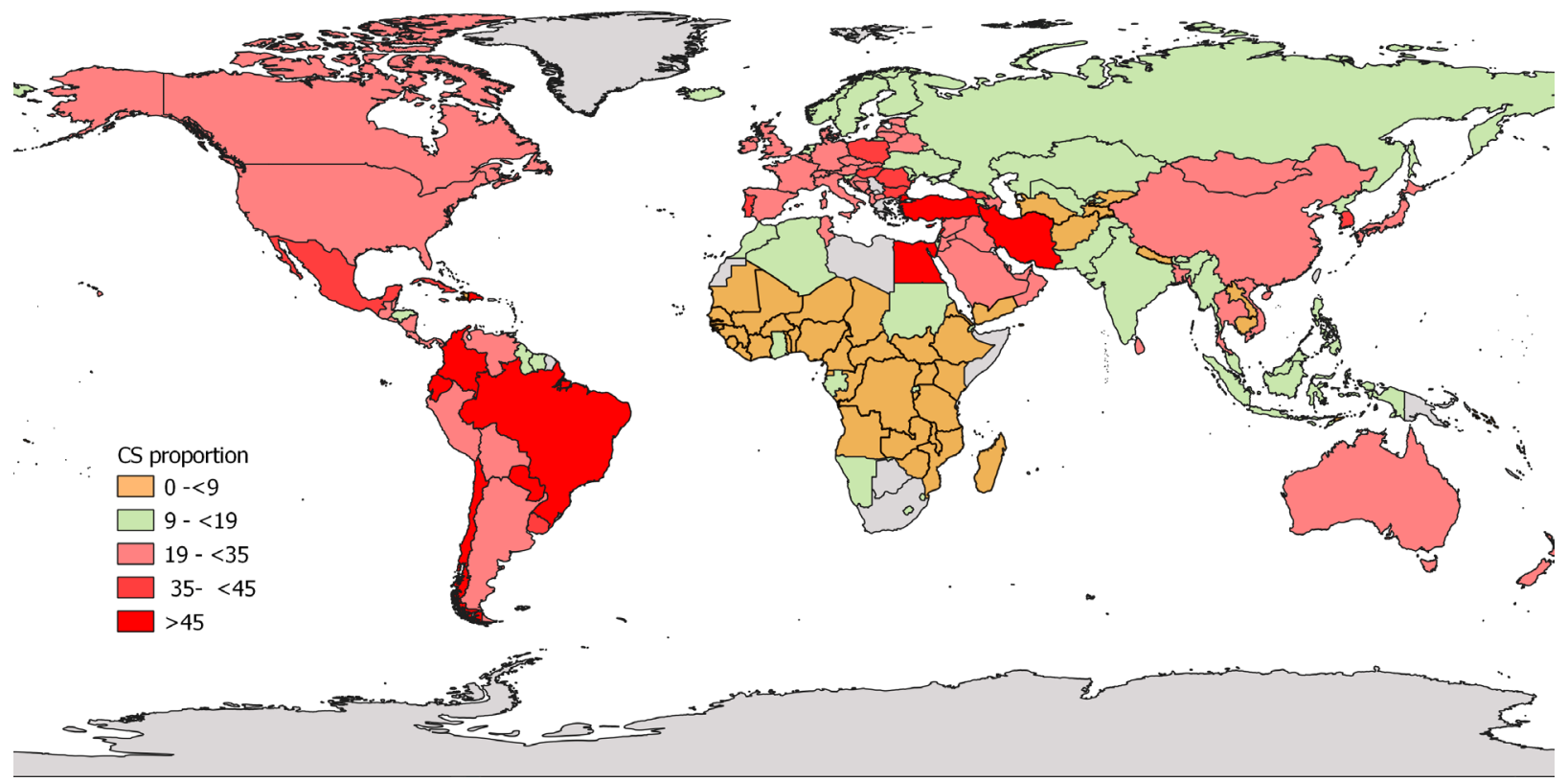

Figure 1 Global distribution of caesarean birth proportions. CS, caesarean section.

control variables, we used Stata's multiple imputation with chained equations algorithm.

\section{Sensitivity analysis}

To ensure the results are not disproportionately shaped by specific regions, we estimate separate models by country-income group in our sensitivity analysis. All analysis was conducted using the Stata V.15 SE statistical software package.

\section{Patient and public involvement statement}

Our study does not directly use data from patients. We used only the WHO and the World Bank data published online.

\section{RESULTS}

Figure 1 shows the distribution of caesarean proportions for the 172 countries with data available. CS proportions varied between 0.5 per cent in South Sudan and 58.1 per cent in the Dominican Republic. At the regional level, lowest proportions were observed for the WHO Africa region (mean 7 per cent) and highest proportions were found for the Americas, with an average proportion of 31.8 per cent. Ninety countries (52 per cent) had CS proportions $\leq 19 \%$, and 82 countries (48per cent) had proportions above the target range.

Table 1 provides summary statistics for our sample. Countries with CS proportions $>19 \%$ were on average substantially wealthier, and had higher obstetrician and midwife densities, while overall health expenditure as percentage of gross domestic product (GDP) was relatively similar in the two subgroups $(6.5 \mathrm{vs} 7.2 \%$, p value 0.112). Countries with CS proportions $>19 \%$ had substantially higher average rates of out-of-pocket expenditures as well as mandatory and voluntary insurance contributions. The correlation between all variables used is shown in the online supplemental appendix. The highest bivariate correlation was found between midwife density and GDP per capita (0.79) —no evidence of multicollinearity was found in the regression models.

Overall, using a 19 per cent benchmark, we estimate that there were 8.8 million unnecessary CS in 2018. Table 2 summarises the global distribution of CS and percentage excess CS using the World Bank's country income classification for the 172 countries in our sample. Given that most countries with missing data in the GHO have low populations, the 172 countries in our sample covered 97 per cent of the global births in 2018. While low-income countries did not contribute at all to percentage excess provision of CS in that year, overprovision was common in lower middle-income countries. Overall, lower middleincome countries accounted for 48 per cent of all births in 2018, and for 18 per cent of all percentage excess CS. Upper middle-income countries account for 25 per cent of all births, but for 67 per cent of all percentage excess CS. Using 9 per cent as a benchmark, we estimate a total of 17 million of unnecessary CS. Trends across country income groups mimic the main findings with 19 per cent benchmark.

Table 3 shows the main regression results. There are three sets of results. We first show results for our main outcome measure, that is, percentage excess using 19 per cent benchmark. The other two sets included results for additional outcomes, that is, percentage excess using 9 per cent benchmark and the absolute CS proportion. When we pooled all private contributions in column 1, we found a small positive association between private contributions and CS excess. A coefficient of 0.08 implies that countries with 100 per cent private financing have on average 8 per cent higher excess CS proportions than countries relying fully on government financing. When we split private contributions into their three components in column 2, 


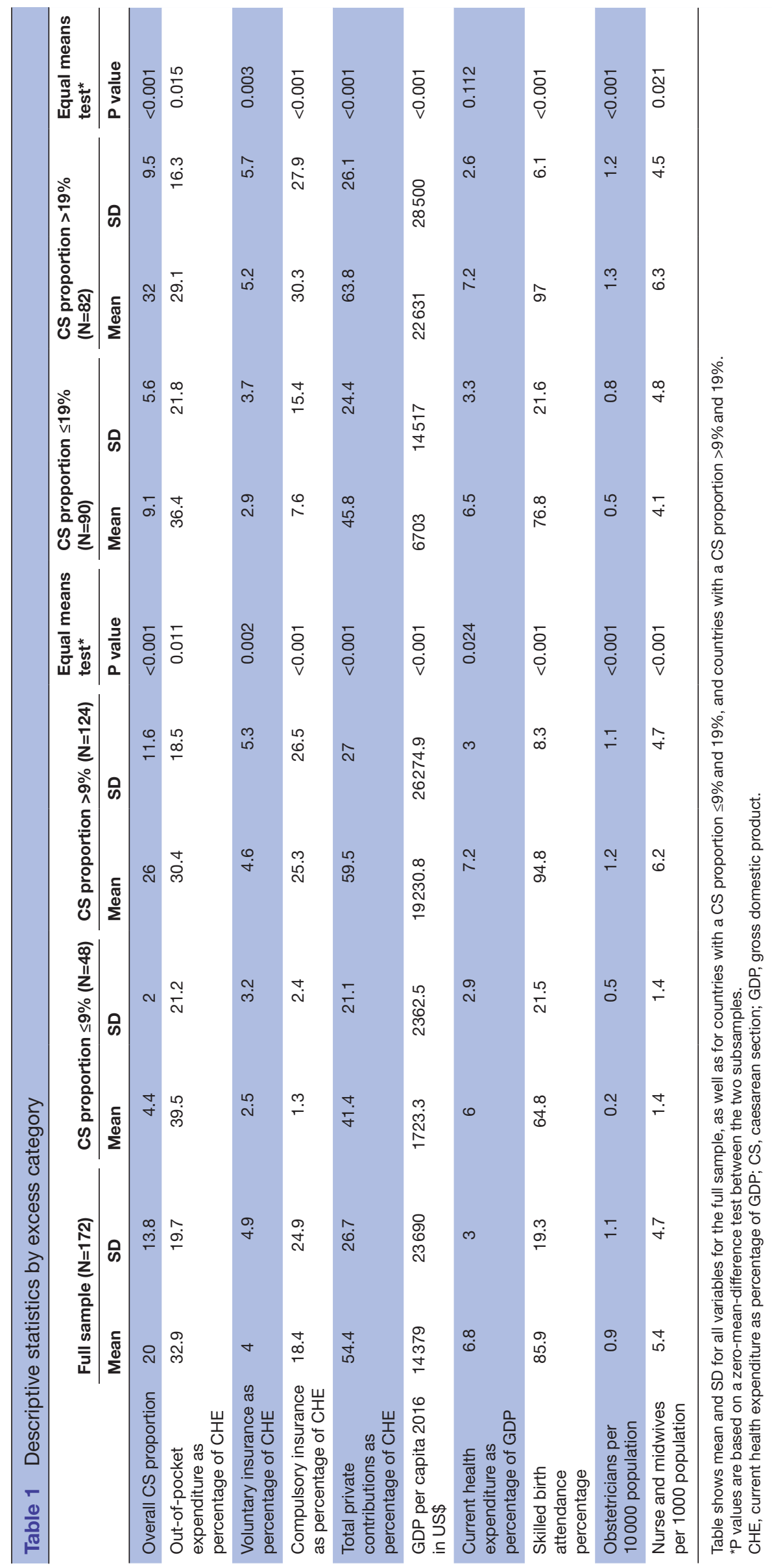

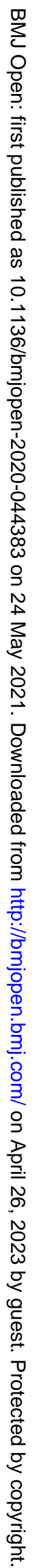


Table 2 Distribution of birth, percentage excess of CS across country income groups

\begin{tabular}{lclllll}
\hline Country income group & $\begin{array}{l}\text { Number of } \\
\text { countries }\end{array}$ & $\begin{array}{l}\text { Total } \\
\text { population } \\
\text { (millions) }\end{array}$ & $\begin{array}{l}\text { Total number of } \\
\text { births per year } \\
\text { (millions) }\end{array}$ & $\begin{array}{l}\text { Average CS } \\
\text { share (\% of } \\
\text { births) }\end{array}$ & $\begin{array}{l}\text { Percentage excess } \\
\text { number of CS 9\% } \\
\text { (millions) }\end{array}$ & $\begin{array}{l}\text { Percentage excess } \\
\text { number of CS 19\% } \\
\text { (millions) }\end{array}$ \\
\hline Low income & 30 & 667 & 23 & 4.7 & 0 & 0 \\
\hline Lower middle income & 49 & 3087.7 & 66.7 & 15.3 & 5.2 & 1.6 \\
Upper middle income & 46 & 2523.5 & 34.6 & 27.9 & 9.2 & 5.9 \\
\hline High income & 47 & 1186.1 & 12.9 & 27 & 2.6 & 1.3 \\
Total & 172 & 7464.3 & 137.2 & 20 & 17 & 8.8 \\
\hline
\end{tabular}

CS, caesarean section.

we found that this overall association is primarily driven by voluntary insurance mechanisms. When controlling only for GDP per capita and the size of the health sector in table 3, column 2, we found no associations for outof-pocket expenditure, a moderate sized coefficient for compulsory contributions and a rather large coefficient for voluntary health insurance: each 10 per cent increase in voluntary health insurance contributions is associated with a 5.6 per cent increase in excess CS proportions. These associations change only marginally when adjusting for general reproductive and health access variables in table 3, columns 3 and 4 . Effects are similar or even more pronounced if we use percentage excess with 9 per cent benchmark or continuous CS proportions.

Table 4 shows the main results of our sensitivity analysis. When we split our sample by country income groups, we find the largest associations in all categories for the upper-middle income group, and the weakest in the lowincome group. Due to the small sample sizes the precision of these estimates is however very low (all $\mathrm{p}$ values $>0.1$ ) for all outcome measures we used.

\section{DISCUSSION}

Consistent with previous papers highlighting the increasing global trend of increasing CS proportions ${ }^{2-9}$ we have found a striking number of CS that seem unnecessary. Using a relatively conservative 19 per cent CS rate benchmark, we estimate that 8.8 million unnecessary CS were carried out in 2018. The vast majority of these percentage excess CS occurred in upper-middle income countries. Belizán et al using a 15 per cent benchmark, with data between 1993 and 1997 estimated that over 850000 unnecessary CS are performed each year in Latin America. ${ }^{8}$ Gibbons et al looking at 137 countries, using a 15 per cent benchmark and data from 2008, estimated that 6.2 million unnecessary CS are performed each year, with China and Brazil accounting for close to $50 \%$ of this global total. With a 20 per cent benchmark rate, there was an estimate of 4 million of unnecessary CS a year. ${ }^{6}$ Our estimates are about 30 per cent higher than these previous numbers may represents both a growing number of births each year and a continued rise in CS rates in middle-income settings.
Studies looking at global CS trends have highlighted the associations between CS and maternal and newborn mortality, ${ }^{5}{ }^{18-20}$ socioeconomic status of women, ${ }^{39}$ private sector care ${ }^{8938}$ and economic growth. ${ }^{48}$ Our results suggests that health financing mechanisms may play a key role in explaining the large differences across countries. We show that, on average, countries relying on private financing have higher CS rates. These associations are particularly pronounced for voluntary health insurance schemes, which generally are used to 'top up' basic health plans and allow users to use premium features. Health insurance, by incentivising healthcare providers, ${ }^{125-27}$ is known to encourage the overuse of CS. ${ }^{26} 39$

In general, higher CS rates should be expected in higher income countries due to increased resources ${ }^{1740}$ or supply sensitive care. ${ }^{1740}$ Similar to previous studies, ${ }^{48}$ we find that national CS rates increase with income. We find however that this positive gradient is only observable up to the middle-income category, and flat or even declining in higher income settings. The generally positive trends can be attributed to a large number of factors, including an increasing proportion of births occurring in health facilities $^{9}$ or attended by trained health personnel, ${ }^{7}$ different work force composition ${ }^{41-45}$ and different technology. ${ }^{46}$

Increases in CS rates are a result of multitude of factors ${ }^{123}$ that interact in complex ways. As such, results of ecological studies should be interpreted with caution, and in the context of the specific systems analysed. For example, private insurance and private sector care often overlap at the country level, and both are likely to contribute to the use of care in general and CS in particular. ${ }^{25-27}$ Studies looking at cross-country comparisons have documented the impact of private care. Belizán et al looking at 19 Latin American countries, observed a positive correlation between private hospitals and the rate of CS. ${ }^{8}$ Boerma et al, on the basis of data from 169 countries, ${ }^{9}$ and Benova et al looking at 57 countries, ${ }^{38}$ concluded similarly. Another example of complexities in interaction of health system factors as they influence service delivery, is explanation of social inequalities in CS rates. Social inequalities in CS rates highlighted by Boatin $e t a \hat{P}$ and Boerma et at also suggest the important influences of economic and cultural issues. ${ }^{37} 47-51$ Supply factors, such as hospital beds, equipment and human resources (ie, 


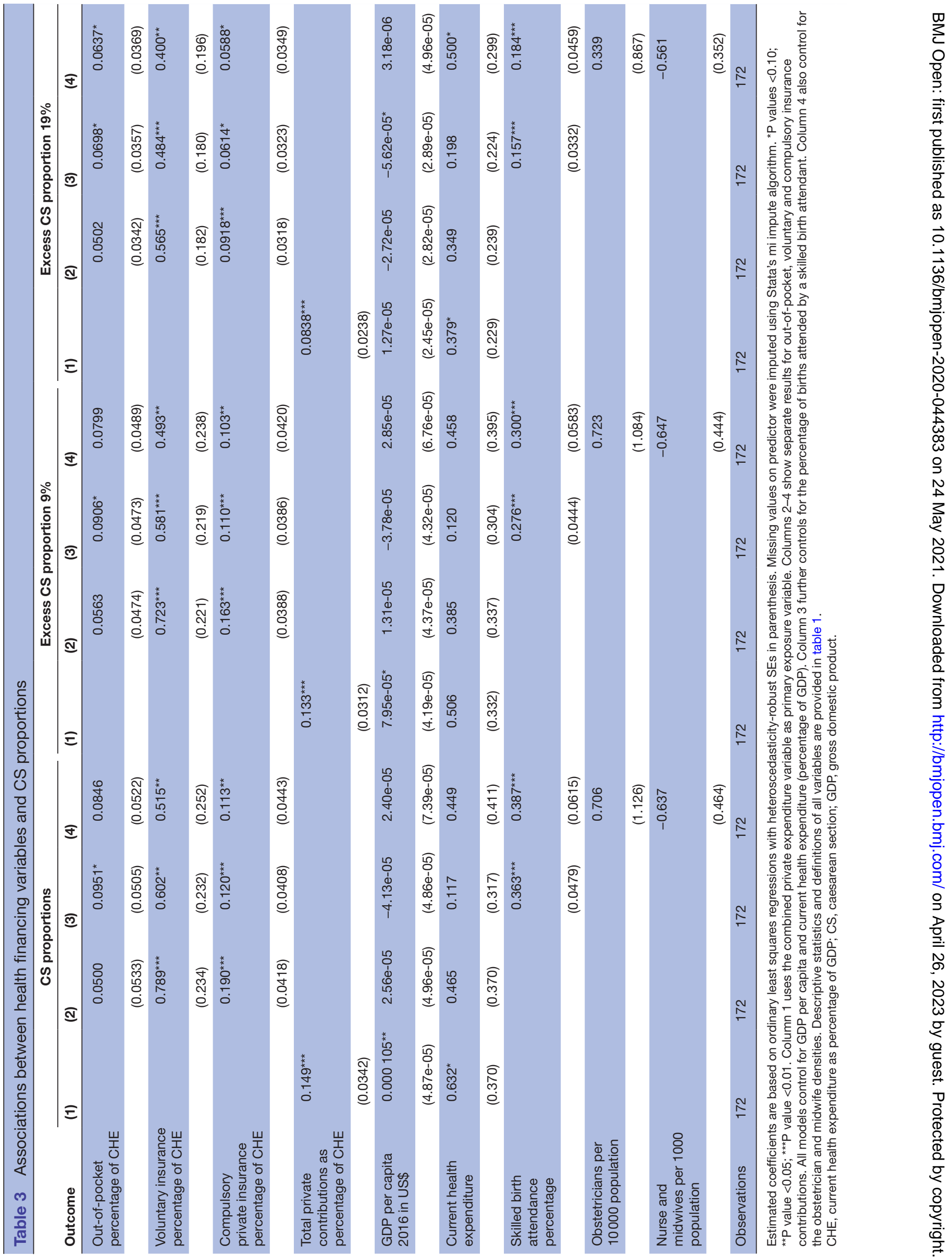




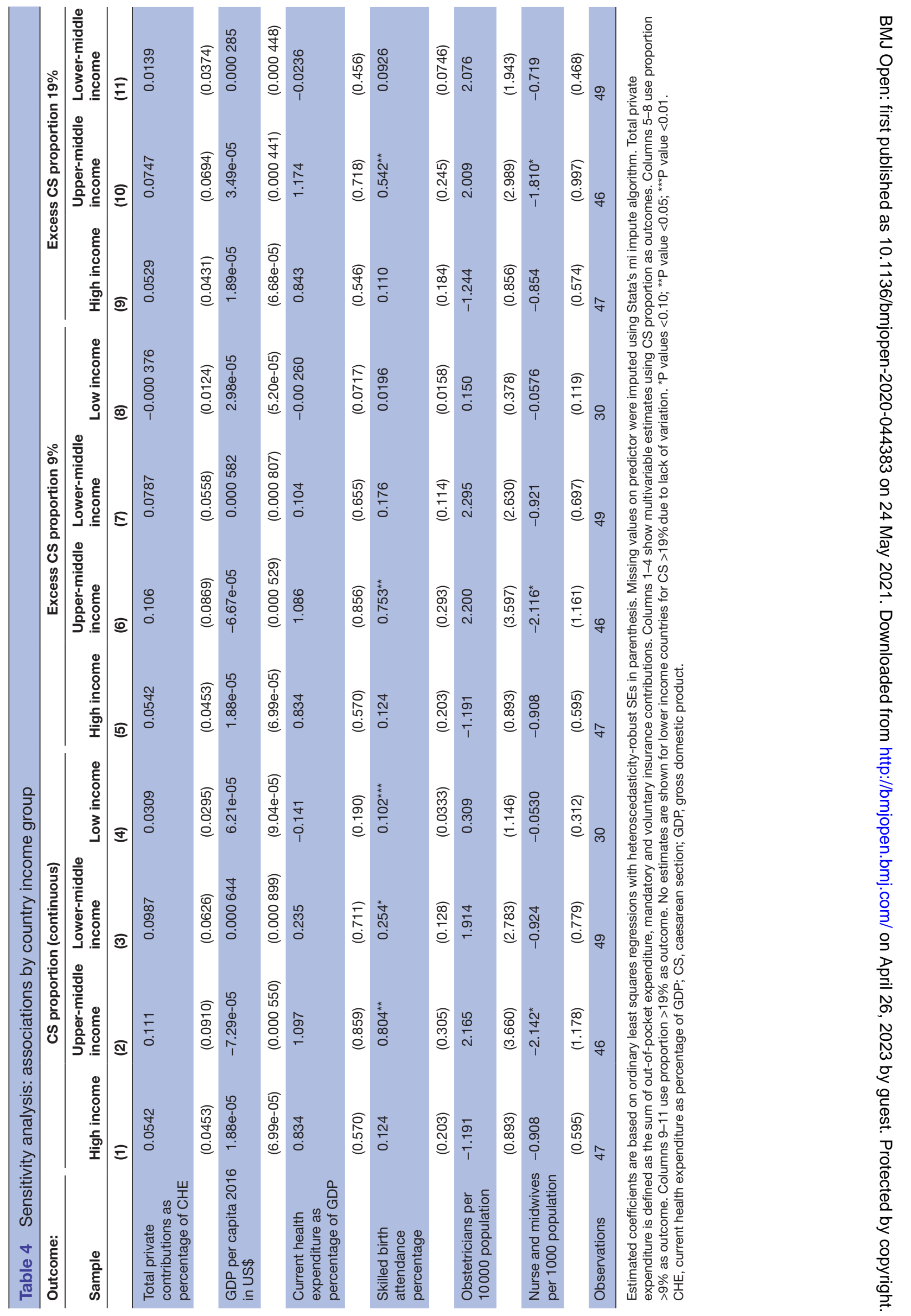


obstetricians and midwives) are also known to influence CS rates. ${ }^{15253}$ The lack of decreasing CS rates with lower numbers of skilled birth attendants in Latin American countries, as compared with other countries with lower skilled birth attendant numbers, ${ }^{7}$ may reflect cultural and social trends in such countries, and is an useful example to illustrate the complexity of the interplay and influence of health system factors in CS rates.

The ecological nature of study design is the main limitation of this study, as we cannot establish a causal relationship between our variables of interest. Although we used some of most reliable internationally available data sources from the WHO and the World Bank, we should be aware that the quality of such data may not be entirely uniform across countries included in the analysis. Finally, we have been able to adjust only for some confounders in our statistical models. There are many other macro level factors (ie, societal and cultural factors) that do play a role and we have not accounted in our analysis.

The exploratory results in this paper should be viewed as a first step towards an in-depth analysis of current health financing systems and their implications for sustainable provision of care in the future. Several pathways forward seem possible. First, global studies with larger and more detailed data on health system characteristics generated from global monitoring systems. Second, performing systematic reviews of individual studies looking at CS rates and health system factors. CS is one of the most studied procedures globally. Evidence synthesis in the form of systematic reviews could serve not just the cause of addressing CS increase and variation but can also prove to be a reference point in the general cause of examining health system influence on under and overuse of medical care. Finally, country specific analysis or even regional or facility level analysis looking at individual case data will be able to establish conclusive links of health system features with CS provision. ${ }^{25} 27$ This information can inform national policy efforts as well as global efforts for improvement of health system financing arrangements. Not all nations may be able to engage in research on optimal financial incentives despite persisting problems with $\mathrm{CS} .{ }^{54}$ Global collaborations to support countries struggling with these issues might be beneficial.

\section{CONCLUSIONS}

The results presented in this study suggest that,on average, countries relying more heavily on private contributions and voluntary health insurance have higher proportions of excess CS. Further research will be needed to better understand features driving these results and to help countries move towards more efficient use of health system resources.

Acknowledgements We thank Riaz Agahi for editing this manuscript and Arber Lama for support with literature search.
Contributors $\mathrm{HH}$ and GF developed and designed the study, retrieved the data from the indicated sources, analysed and interpreted the data and jointly drafted the manuscript.

Funding The authors have not declared a specific grant for this research from any funding agency in the public, commercial or not-for-profit sectors.

Map disclaimer The depiction of boundaries on the map(s) in this article does not imply the expression of any opinion whatsoever on the part of BMJ (or any member of its group) concerning the legal status of any country, territory, jurisdiction or area or of its authorities. The map(s) are provided without any warranty of any kind, either express or implied.

Competing interests None declared.

Patient consent for publication Not required.

Provenance and peer review Not commissioned; externally peer reviewed.

Data availability statement Data are available in a public, open access repository. The data used for this study are freely available from the WHO's Global Health Expenditure Database and Global Health Observatory, and from the World Bank Open Data.

Supplemental material This content has been supplied by the author(s). It has not been vetted by BMJ Publishing Group Limited (BMJ) and may not have been peer-reviewed. Any opinions or recommendations discussed are solely those of the author(s) and are not endorsed by BMJ. BMJ disclaims all liability and responsibility arising from any reliance placed on the content. Where the content includes any translated material, BMJ does not warrant the accuracy and reliability of the translations (including but not limited to local regulations, clinical guidelines, terminology, drug names and drug dosages), and is not responsible for any error and/or omissions arising from translation and adaptation or otherwise.

Open access This is an open access article distributed in accordance with the Creative Commons Attribution Non Commercial (CC BY-NC 4.0) license, which permits others to distribute, remix, adapt, build upon this work non-commercially, and license their derivative works on different terms, provided the original work is properly cited, appropriate credit is given, any changes made indicated, and the use is non-commercial. See: http://creativecommons.org/licenses/by-nc/4.0/.

\section{ORCID iD}

Ilir Hoxha http://orcid.org/0000-0003-4262-1406

\section{REFERENCES}

1 Hoxha I, Busato A, Luta X. Medical practice variations in reproductive, obstetric, and gynecological care. In: Johnson A, Stukel TA, eds. Medical practice variations. Boston, MA: Springer US, 2016: 141-60.

2 Betrán AP, Ye J, Moller A-B, et al. The increasing trend in caesarean section rates: global, regional and national estimates: 1990-2014. PLoS One 2016;11:e0148343.

3 Boatin AA, Schlotheuber A, Betran AP, et al. Within country inequalities in caesarean section rates: observational study of 72 low and middle income countries. BMJ 2018;360:k55.

4 Althabe F, Sosa C, Belizán JM, et al. Cesarean section rates and maternal and neonatal mortality in low-, medium-, and high-income countries: an ecological study. Birth 2006;33:270-7.

5 Molina G, Weiser TG, Lipsitz SR, et al. Relationship between cesarean delivery rate and maternal and neonatal mortality. JAMA 2015;314:2263-70.

6 Gibbons L, Belizan JM, Lauer JA, et al. Inequities in the use of cesarean section deliveries in the world. Am J Obstet Gynecol 2012;206:331.e1-9.

7 Betrán AP, Merialdi M, Lauer JA, et al. Rates of caesarean section: analysis of global, regional and national estimates. Paediatr Perinat Epidemiol 2007;21:98-113.

8 Belizán JM, Althabe F, Barros FC, et al. Rates and implications of caesarean sections in Latin America: ecological study. BMJ 1999;319:1397-400.

9 Boerma T, Ronsmans C, Melesse DY, et al. Global epidemiology of use of and disparities in caesarean sections. Lancet 2018;392:1341-8.

10 De Brouwere V, Dubourg D, Richard F, et al. Need for caesarean sections in West Africa. Lancet 2002;359:974-5.

11 Dumont $A$, de Bernis L, Bouvier-olle $M-H$, et al. Caesarean section rate for maternal indication in sub-Saharan Africa: a systematic review. Lancet 2001;358:1328-33. 
12 Pyykönen A, Gissler M, Løkkegaard E, et al. Cesarean section trends in the Nordic Countries - a comparative analysis with the Robson classification. Acta Obstet Gynecol Scand 2017;96:607-16.

13 Katikireddi SV, Gorman DR, Leyland AH. A comparison of trends in caesarean section rates in former communist (transition) countries and other European countries. Eur J Public Health 2013;23:381-3.

14 Ronsmans C, Holtz S, Stanton C. Socioeconomic differentials in caesarean rates in developing countries: a retrospective analysis. Lancet 2006;368:1516-23.

15 Zeitlin J, Szamotulska K, Drewniak N, et al. Preterm birth time trends in Europe: a study of 19 countries. BJOG: Int J Obstet Gy 2013;120:1356-65.

16 Saini V, Brownlee S, Elshaug AG, et al. Addressing overuse and underuse around the world. Lancet 2017;390:105-7.

17 Wennberg JE. Tracking medicine : a researcher's quest to understand health care. 1st edn. Oxford: Oxford University Press, 2011.

18 Betran AP, Torloni MR, Zhang JJ, et al. WHO Statement on Caesarean Section Rates. BJOG 2016;123:667-70.

19 Appropriate technology for birth. Lancet 1985;2:436-7.

20 Betran AP, Torloni MR, Zhang J, et al. What is the optimal rate of caesarean section at population level? A systematic review of ecologic studies. Reprod Health 2015;12:57.

21 Belizán JM, Althabe F, Cafferata ML. Health consequences of the increasing caesarean section rates. Epidemiology 2007;18:485-6.

22 Keag OE, Norman JE, Stock SJ. Long-term risks and benefits associated with cesarean delivery for mother, baby, and subsequent pregnancies: systematic review and meta-analysis. PLoS Med 2018;15:e1002494.

23 Betrán AP, Temmerman M, Kingdon C, et al. Interventions to reduce unnecessary caesarean sections in healthy women and babies. Lancet 2018;392:1358-68.

24 Wennberg JE, Barnes BA, Zubkoff M. Professional uncertainty and the problem of supplier-induced demand. Soc Sci Med 1982;16:811-24.

25 Hoxha I, Syrogiannouli L, Luta X, et al. Caesarean sections and forprofit status of hospitals: systematic review and meta-analysis. BMJ Open 2017;7:e013670.

26 Hoxha I, Braha M, Syrogiannouli L, et al. Caesarean section in uninsured women in the USA: systematic review and meta-analysis. BMJ Open 2019;9:e025356.

27 Hoxha I, Syrogiannouli L, Braha M, et al. Caesarean sections and private insurance: systematic review and meta-analysis. BMJ Open 2017;7:e016600.

28 de Regt RH, Minkoff HL, Feldman J, et al. Relation of private or clinic care to the cesarean birth rate. N Engl J Med 1986;315:619-24.

29 de Regt $\mathrm{RH}$, Marks K, Joseph DL, et al. Time from decision to incision for cesarean deliveries at a community hospital. Obstet Gynecol 2009;113:625-9.

30 Bertollini R, DiLallo D, Spadea T, et al. Cesarean section rates in Italy by hospital payment mode: an analysis based on birth certificates. Am J Public Health 1992;82:257-61.

31 Stafford RS. Cesarean section use and source of payment: an analysis of California hospital discharge Abstracts. Am J Public Health 1990;80:313-5.

32 Goldfield N, Averill R, Vertrees J, et al. Reforming the primary care physician payment system: eliminating $E$ \& $M$ codes and creating the financial incentives for an "advanced medical home". J Ambul Care Manage 2008;31:24-31.

33 Keeler EB, Brodie M. Economic incentives in the choice between vaginal delivery and cesarean section. Milbank Q 1993;71:365-404.

34 Bland ES, Oppenheimer LW, Holmes P, et al. The effect of income pooling within a call group on rates of obstetric intervention. CMAJ 2001;164:337-9.
35 Grant D. Explaining source of payment differences in U.S. cesarean rates: why do privately insured mothers receive more cesareans than mothers who are not privately insured? Health Care Manag Sci 2005;8:5-17.

36 Grant D. Physician financial incentives and cesarean delivery: new conclusions from the healthcare cost and utilization project. $J$ Health Econ 2009;28:244-50.

37 Hoxha I, Fejza A, Aliu M, et al. Health system factors and caesarean sections in Kosovo: a cross-sectional study. BMJ Open 2019;9:e026702.

38 Benova L, Macleod D, Footman K, et al. Role of the private sector in childbirth care: cross-sectional survey evidence from 57 low- and middle-income countries using demographic and health surveys. Trop Med Int Health 2015;20:1657-73.

39 Mossialos E, Allin S, Karras K. An investigation of caesarean sections in three Greek hospitals: the impact of financial incentives and convenience. Eur J Public Health 2005;15:288-95.

40 Fisher ES, Wennberg JE. Health care quality, geographic variations, and the challenge of supply-sensitive care. Perspect Biol Med 2003;46:69-79.

41 Chang C-Het al. Primary care physician workforce and Medicare beneficiaries' health outcomes. JAMA 2011;305:2096-104.

42 de Jonge A, Peters L, Geerts CC, et al. Mode of birth and medical interventions among women at low risk of complications: a crossnational comparison of birth settings in England and the Netherlands PLoS One 2017;12:e0180846.

43 Zhihua W, Wenchao S, Hong Z. Midwife-led care model for reducing caesarean rate: a novel concept for worldwide birth units where standard obstetric care still dominates 2012;6:28-31.

44 Pel M, Heres MHB, Hart AAM, et al. Provider-associated factors in obstetric interventions. Eur J Obstet Gynecol Reprod Biol 1995;61:129-34.

45 Chapman A, Nagle C, Bick D, et al. Maternity service organisational interventions that AIM to reduce caesarean section: a systematic review and meta-analyses. BMC Pregnancy Childbirth 2019;19:206.

46 Grytten J, Monkerud L, Sørensen R. Adoption of diagnostic technology and variation in caesarean section rates: a test of the practice style hypothesis in Norway. Health Serv Res 2012;47:2169-89.

47 Savage W. The rise in cesarean section: anxiety or science? In: Chard T, Richards MPM, eds. Obstetrics in the 1990s: current controversies. London, UK: Cambridge University Press, 1992.

48 Johnson SR, Elkins TE, Strong C. Obstetric decision-making: responses to patients who request cesarean delivery. Obstet Gynecol 1986;67:847-50.

49 Joseph GF, Stedman CM, Robichaux AG. Vaginal birth after cesarean section: the impact of patient resistance to a trial of labor. Am Obstet Gynecol 1991;164:1441-7.

50 Ramires de Jesus G, Ramires de Jesus N, Peixoto-Filho FM, et al. Caesarean rates in Brazil: what is involved? BJOG: Int J Obstet Gy 2015;122:606-9.

51 Barros FC, Vaughan JP, Victora CG. Why so many caesarean sections? The need for a further policy change in Brazil. Health Policy Plan 1986;1:19-29.

52 Sandall J, Soltani H, Gates S, et al. Midwife-led continuity models versus other models of care for childbearing women. Cochrane Database Syst Rev 2016;4:CD004667.

53 Hoxha I, Sadiku F, Lama A, et al. Cesarean delivery and gender of delivering physicians: a systematic review and meta-analysis. Obstet Gynecol 2020;136:1170-8.

54 Brüggmann D, Löhlein L-K, Louwen F, et al. Caesarean section -a density-equalizing mapping study to Depict its global research architecture. Int J Environ Res Public Health 2015;12:14690-708. 